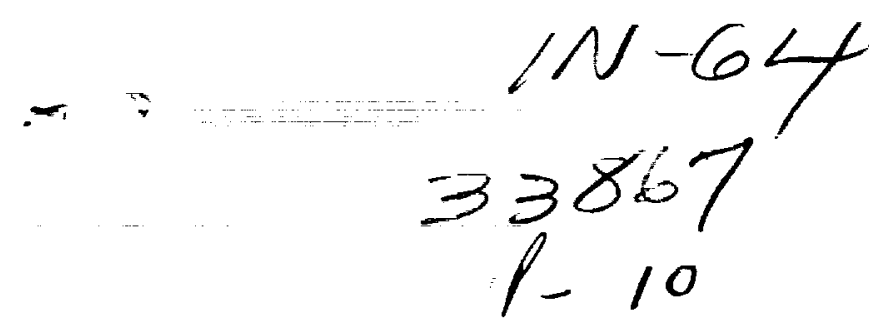

ICASE Report No. 94-79
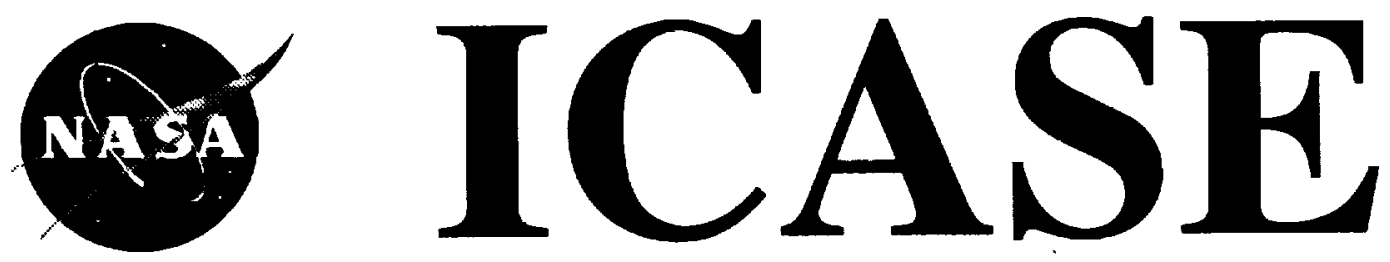

\title{
ON THE REMOVAL OF BOUNDARY ERRORS CAUSED BY RUNGE-KUTTA INTEGRATION OF NON-LINEAR PARTIAL DIFFERENTIAL EQUATIONS
}

Saul Abarbanel

David Gottlieb

Mark H. Carpenter

Contract NAS1-19480

September 1994

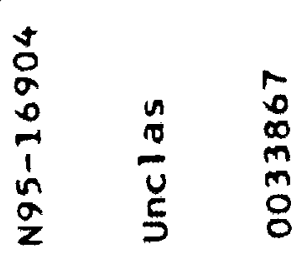

Institute for Computer Applications in Science and Engineering NASA Langley Research Center Hampton, VA 23681-0001
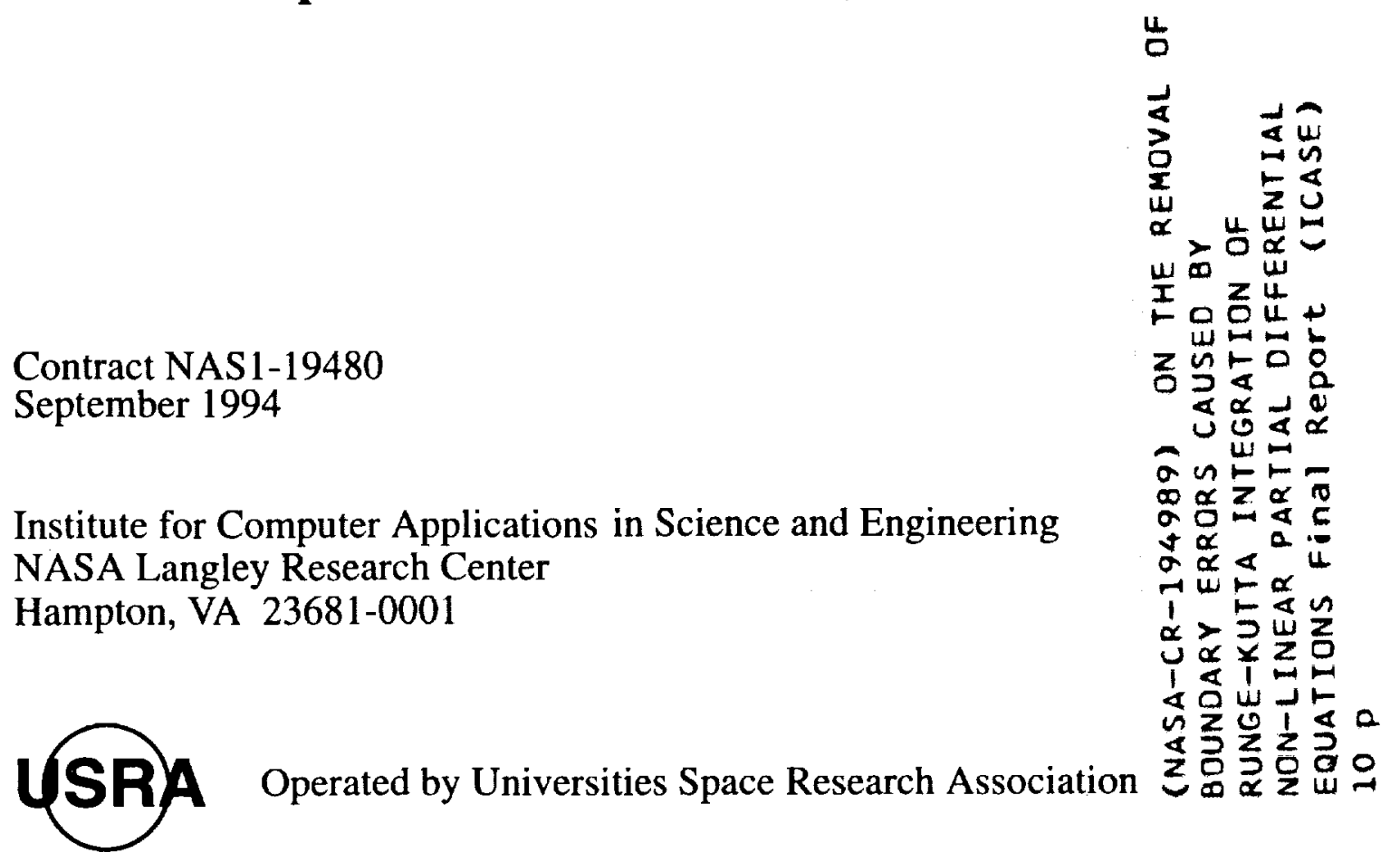
$=\ldots$ 


\title{
ON THE REMOVAL OF BOUNDARY ERRORS \\ CAUSED BY RUNGE-KUTTA INTEGRATION OF \\ NON-LINEAR PARTIAL DIFFERENTIAL EQUATIONS ${ }^{1}$
}

\author{
Saul Abarbanel \\ Department of Mathematical Sciences \\ Division of Applied Mathematics \\ Tel-Aviv University \\ Tel-Aviv, ISRAEL \\ David Gottlieb ${ }^{1}$ \\ Division of Applied Mathematics \\ Brown University \\ Providence, RI 02912 \\ Mark H. Carpenter \\ Theoretical Flow Physics Branch \\ Fluid Mechanics Division \\ NASA Langley Research Center \\ Hampton, VA 23681-0001
}

\begin{abstract}
It has been previously shown that the temporal integration of hyperbolic partial differential equations may, because of boundary conditions, lead to deterioration of accuracy of the solution. A procedure for removal of this error in the linear case has been established previously.

In the present paper we consider hyperbolic p.d.e's (linear and non-linear) whose boundary treatment is done via the SAT-procedure. A methodology is present for recovery of the full order of accuracy, and has been applied to the case of a 4 th order explicit finite difference scheme.
\end{abstract}

\footnotetext{
${ }^{1}$ This research was supported by the National Aeronautics and Space Administration under NASA Contract No. NAS1-19480 while the authors were in residence at the Institute for Computer Applications in Science and Engineering (ICASE), NASA Langley Research Center, Hampton, VA 23681. The second author was supported also by AFOSR 93-0090 ARPA grant N00014-91-J-4016 and NSF grant DMS - 9211820
} 


\section{Introduction}

Currently there is a growing interest in long time integration for solving problems in areas such a aero-acoustics, electro-magnetics, material-science and others. This necessitates, ([1]), working with higher order (4th order accuracy and above) schemes. Often the methodology of choice is to semi-discretize the equations by applying a high order (4th and above) spatial difference operator and then advance temporally using single level multi-stage Runge-Kutta integrators. This raises the question of how to supply boundary values at the intermediate stages of the R-K integrations. In the case of hyperbolic p.d.e's that means the imposition of the time dependent conditions at the inflow boundary.

The conventional (and intuitively natural) way of imposing inflow boundary conditions at the intermediate stages is to use the "appropriate" value of the boundary data, $g(t)$, at each stage. Thus, for example, at a stage corresponding to $t+(\Delta t / 2)$, one would impose $g(t+\Delta t / 2)$.

In a previous paper ([2]), it was shown that the procedure described above, when applied to hyperbolic p.d.e's with time dependent b.c.'s, reduces the accuracy near the inflow boundary to first order and thus the overall accuracy cannot exceed $0\left(\Delta x^{2}\right)$. This conclusion is independent of the order of accuracy of the spatial difference operator.

One way of avoiding the dilemma of what boundary values one should supply at the intermediate stages, is to advance the R-K integration without imposing any intermediate values, but rather obtain the intermediate boundary values from the numerical solution operator. However, this approach has the disadvantage of reducing substantially the stability limit (e.g., the allowable time step is reduced by a factor 2 in the case of 4th order classical $\mathrm{R}-\mathrm{K}$ with a 4th order spatial derivative operator), hence rendering it less than attractive.

In ([2]) a general methodology was presented in the case of linear p.d.e.'s for the correct imposition of the intermediate stage boundary values so that the scheme recovers its full formal accuracy. This was expounded in detail for the case of the classic 4th order R-K with a hyperbolic 4 th order spatial difference operator. It was also shown there that in the non-linear case (e.g. hyperbolic conservation laws) this methodology was applicable to R-K integration up to 3 rd order. For R-K . methods of 4 th order and above we were not able to extend the theoretical approach described in ( [2]).

In this paper we address anew the issue of how to deal with the non-linear case. We present a methodology for retaining the full accuracy even in the non-linear case. The application of this methodology involved numerical determination of free parameters in contradistinctsr numerical determination of free parameters in contradistinction to the linear procedure described in ([2]). We find for example, that in the 4th order classical R-K integrator with 4th order explicit spatial derivative operator, the full accuracy is retained without 
any reduction in $\mathrm{t}$ he allowable time step.

The new procedure is demonstrated for hyperbolic problems where the boundary conditions are satisfied by using the SAT approach ([3]. The motivation for doing so is that the SAT procedure is the only one that prevents temporal growth not present in the true solution of a system of p.d.e.'s. Section 2 describes how to apply correctly the intermediate SAT boundary conditions in the case of a linear problem. In Section 3 we cover the non-linear case.

\section{The Linear Case}

In this section we analyze the effect of imposing the inflow boundary conditions in the conventional way when the discretization algorithm employs the SAT approach (see ([3])). The SAT is a penalty type method that was constructed so as to ensure that the numerical solution will not include temporal growth which is not of a physical origin. This is achieved by mimicking the energy estimate of the p.d.e.

Recall that we are considering the following hyperbolic problem (see ([3])):

$$
\begin{gathered}
\frac{\partial u}{\partial t}+\frac{\partial u}{\partial x}=0, \quad 0 \leq x \leq t, t \geq 0 \\
u(0, t)=g(t)
\end{gathered}
$$

The SAT formulation for the semi-discrete version of (2.1) - (2.2), based on a uniform grid, is

$$
\frac{d v_{i}(t)}{d t}=\left(\frac{1}{h} D \vec{V}(t)\right)_{i}-\frac{1}{h} \tau \vec{\sigma}\left(v_{0}(t)-g(t)\right), \quad i=0,1, \ldots, N ; \quad t \geq 0
$$

where $\vec{V}=\left[v_{0}, v_{1}, \ldots, v_{N}\right]^{T}$ is the semi-discrete approximation that converges to $u\left(x_{i}, t\right)$ at the spatial grid points $x_{i}$ (for stable discretizations); and $\frac{1}{h} D$ is the differential matrix representation of the derivative operator $\left(-\frac{\partial}{\partial x}\right)$. The vector $\vec{\sigma}$ depends on the differentiation matrix $\frac{1}{h} D$, and on the energy norm used in bounding the error. It is determined as described in ([3]); see the discussion after equation (6) therein.

The demonstration of accuracy deterioration will be shown for the four stage "classical" RK algorithm, which is one of the most commonly used RK time advancing schemes. For the analysis to make sense we assume that the spatial discretization is at least fourth order accurate.

The above mentioned four stage RK integrator is implemented as follows:

$$
V^{(1)}=V^{(n)}+\frac{\lambda}{2} D V^{(n)}-\frac{\lambda}{2} \tau \vec{\sigma}\left[v_{0}^{(n)}-g(t)\right]
$$




$$
\begin{gathered}
V^{(2)}=V^{(n)}+\frac{\lambda}{2} D V^{(1)}-\frac{\lambda}{2} \tau \vec{\sigma}\left[v_{0}^{(1)}-g\left(t+\frac{\Delta t}{2}\right)\right] \\
V^{(3)}=V^{(n)}+\lambda D V^{(2)}-\lambda \tau \vec{\sigma}\left[v_{0}^{(2)}-g\left(t+\frac{\Delta t}{2}\right)\right] \\
V^{(n+1)}=V^{(n)}+\frac{\lambda}{6} D\left[V^{(n)}+2 V^{(1)}+2 V^{(2)}+V^{(3)}\right] \\
-\frac{\lambda}{6} \tau \vec{\sigma}\left\{\left[v_{0}^{(n)}-g(t)\right]+2\left[v_{0}^{(1)}-g\left(t+\frac{\Delta t}{2}\right)\right]+2\left[v_{0}^{(2)}-g\left(t+\frac{\Delta t}{2}\right)\right]\right. \\
\left.+\left[v_{0}^{(3)}-g(t+\Delta t)\right]\right\} .
\end{gathered}
$$

To clieck for accuracy we substitute for the $V^{(n)}$ the exact values $u\left(x_{i}, t\right)$, and in particular $v_{0}^{(n)}=g(t)$. Note from eq. (2.4), that on the bounclary (using the differential equations $(2.1),(2.2))$

$$
v_{0}^{(1)}=v_{0}^{(n)}-\frac{\Delta t}{2}\left(\frac{\partial}{\partial x} u\right)_{0}=g(t)+\frac{\Delta t}{2} g^{\prime}(t) .
$$

Thus in eq. (2.7), we have for the term $v_{0}^{(1)}-g\left(t+\frac{\Delta t}{2}\right)$,

$$
v_{0}^{(1)}-g\left(t+\frac{\Delta t}{2}\right)=\left[g(t)+\frac{\Delta t}{2} g^{\prime}(t)\right]-g\left(t+\frac{\Delta t}{2}\right)=0\left(\Delta t^{2}\right) .
$$

Thus $V^{(n+1)}-V^{(n)}$ is at best $0\left(\Delta t^{2}\right)$, and not $0\left(\Delta t^{5}\right)$ as expected from the R-K scheme used.

In this linear case, the remedy proposed in the previous paper, ([2]), works here as well. In particular, eqs. (2.4) -(2.7) take the following form:

$$
\begin{gathered}
V^{(1)}=V^{(n)}+\frac{\lambda}{2} D V^{(n)}-\frac{\lambda}{2} \tau \vec{\sigma}\left[v_{0}^{(n)}(t)-g(t)\right] \\
V^{(2)}=V^{(n)}+\frac{\lambda}{2} D V^{(1)}-\frac{\lambda}{2} \tau \vec{\sigma}\left[v_{0}^{(1)}-g(t)-\frac{\Delta t}{2} g^{\prime}(t)\right] \\
V^{(3)}=V^{(n)}+\lambda D V^{(2)}-\lambda \tau \vec{\sigma}\left[v_{0}^{(2)}-g(t)-\frac{\Delta t}{2} g^{\prime}(t)-\frac{\Delta t^{2}}{4} g^{\prime \prime}(t)\right] \\
V^{n+1}=V^{n}+\frac{\lambda}{6} D\left[V^{(n)}+2 V^{(1)}+2 V^{(2)}+V^{(3)}\right] \\
-\frac{\lambda}{6} \tau \sigma\left\{\left[v_{0}^{(n)}-g(t)\right]+2\left[v_{0}^{(1)}-g(t)-\frac{\Delta t}{2} g^{\prime}(t)\right]\right. \\
+2\left[v_{0}^{(2)}-g(t)-\frac{\Delta t}{2} g^{\prime}(t)-\frac{\Delta t^{2}}{4} g^{\prime \prime}(t)\right] \\
\left.+\left[v_{0}^{(3)}-g(t)-\Delta t g^{\prime}-\frac{\Delta t^{2}}{2} g^{\prime \prime}-\frac{\Delta t^{3}}{4} g^{\prime \prime \prime}\right]\right\} .
\end{gathered}
$$

It is readily verified that $V^{(n+1)}-V^{(n)}=0\left(\Delta t^{5}\right)$, as required. 


\section{The Non-Linear Case}

For the sake of simplicity we consider first the scalar conservation law p.d.e.

$$
\begin{gathered}
\frac{\partial u}{\partial t}+\frac{\partial f(u)}{\partial x}=0, \quad 0 \leq x \leq 1 ; \quad t \geq 0 \\
u(0, t)=g(t) .
\end{gathered}
$$

In general, for any spatial discretization (whether explicit or implicit) the semi-discrete form of (3.1) - (3.2) is:

$$
\frac{d V}{d t}=\frac{1}{h} D f(V)-\frac{1}{h} \tau \vec{\sigma}\left[v_{0}-g(t)\right] .
$$

Using the notation of reference ([3]),

$$
D=-P^{-1} Q
$$

where $\frac{1}{h} D$ is the differentiation matrix representing the differential operator, $\left(-\frac{\partial}{\partial x}\right)$; composed of the explicit part $Q$ and the inverse of the implicit part $P$. For a fully explicit spatial differentiation, $P=I+B$, where $B$ differs from zero only at the two diagonal corners (see examples of $P$ and $Q$ in ([4]))..

The vector $\vec{\sigma}$, again using the notation of [ ], is given by

$$
\vec{\sigma}=h a\left(\iota_{0}\right) g_{00} P^{-1} H^{-1} S
$$

where $a\left(u_{0}\right)=\left(\frac{\partial f}{\partial u}\right)_{x=0}$, and $g_{00}$ is twice the value of the left upper corner element of $H Q$. For the definition of the matrix $H$ see Assumption I in [1]. The parameter $\tau$ is determined from stability consideration to be $\tau \geq 1$, see ([3]).

Next we demonstrate that writing the classical 4 th order $R K$ for eq. (3.3), using the linear "fix" as in equations (2.10) - (2.13), does not yield the required 4th order accuracy:

$$
\begin{gathered}
V^{(1)}=V^{(n)}+\frac{\lambda}{2} D f\left(V^{(n)}\right)-\frac{\lambda}{2} \tau \vec{\sigma}\left[v_{0}^{(n)}-g(t)\right] \\
V^{(2)}=V^{(n)}+\frac{\lambda}{2} D f\left(V^{(1)}\right)-\frac{\lambda}{2} \tau \vec{\sigma}\left[v_{0}^{(1)}-g(t)-\frac{\Delta t}{2} g^{\prime}(t)\right] \\
V^{(3)}=V^{(n)}+\lambda D f\left(V^{(2)}\right)-\lambda \tau \vec{\sigma}\left[v_{0}^{(2)}-g(t)-\frac{\Delta t}{2} g^{\prime}(t)-\frac{\Delta t^{2}}{4} g^{\prime \prime}(t)\right]
\end{gathered}
$$




$$
\begin{aligned}
V^{(n+1)}= & V^{(n)}+\frac{\lambda}{6} D\left[f\left(V^{n}\right)+2 f\left(V^{(1)}\right)+2 f\left(V^{(2)}\right)+f\left(V^{(3)}\right)\right] \\
& -\frac{\lambda}{6} \tau \sigma\left\{\left[v_{0}^{(n)}-g(t)\right]+2\left[v_{0}^{(1)}-g(t)-\frac{\Delta t}{2} g^{\prime}(t)\right]\right. \\
& +2\left[v_{0}^{(2)}-g(t)-\frac{\Delta t}{2} g^{\prime}(t)-\frac{\Delta t^{2}}{4} g^{\prime \prime}(t)\right] \\
& \left.+\left[v_{0}^{(3)}-g(t)-\Delta t g^{\prime}-\frac{\Delta t^{2}}{2} g^{\prime \prime}-\frac{\Delta t^{3}}{4} g^{\prime \prime \prime}\right]\right\}
\end{aligned}
$$

Again, when checking accuracy, we take $V^{(n)}=u\left(x_{i}, t\right)$, and in particular $v_{0}^{(n)}=g(t)$; and also $\frac{1}{h} D f\left(V^{n}\right)=-\frac{\partial}{\partial x} f(u)+0\left(\Delta t^{4}\right)$. With these preliminaries we get immediately from equation (3.5)

$$
v_{0}^{(1)}=v_{0}^{n}-\frac{\Delta t}{2} \frac{\partial}{\partial x} f(\mu)_{0}=g(t)+\frac{\Delta t}{2} \frac{\partial}{\partial t}(u)_{0}=g(t)+\frac{\Delta t}{2} g^{\prime}(t) .
$$

Note that this is the same as in the linear case, see eq. (2.8). Thus with $v_{0}^{(n)}=g(t)$ and with equation (3.9) we can supply, for the purpose of accuracy checking, the correct values of $v^{(n)}$ and $v_{0}^{(1)}$. When we look at eq. (3.6), using the above results, the governing non-linear p.d.e., and simple Taylor's expansion, we have:

$$
\begin{aligned}
V^{(2)} & =V^{(n)}+\frac{\lambda}{2} D f\left[V^{(n)}+\frac{\lambda}{2} D f\left(V^{n}\right)\right] \\
& =V^{(n)}-\frac{\Delta t}{2} \frac{\partial}{\partial x} f\left[u-\frac{\Delta t}{2} \frac{\partial}{\partial x} f(u)+0\left(\Delta t^{5}\right)\right]=V^{n}-\frac{\Delta t}{2} \frac{\partial}{\partial x} f\left[u+\frac{\Delta t}{2} \frac{\partial u}{\partial t}+0\left(\Delta t^{5}\right)\right] \\
& =V^{(n)}-\frac{\Delta t}{2} \frac{\partial}{\partial x}\left\{f(u)+\frac{\Delta t}{2} \frac{\partial f}{\partial u} \frac{\partial u}{\partial t}+\frac{\Delta t^{2}}{8}\left(\frac{\partial^{2} f}{\partial u^{2}}\right)\left(\frac{\partial u}{\partial t}\right)^{2}+0\left(\Delta t^{3}\right)\right\} \\
& =V^{(n)}-\frac{\Delta t}{2}\left\{\frac{\partial f}{\partial x}+\frac{\Delta t}{2} \frac{\partial}{\partial t}\left(\frac{\partial f}{\partial x}\right)\right\}+0\left(\Delta t^{3}\right) \\
& =u-\frac{\Delta t}{2}\left[-u_{t}-\frac{\Delta t}{2} u_{t t}\right]+0\left(\Delta t^{3}\right) .
\end{aligned}
$$

So finally we have on the boundary

$$
v_{0}^{(2)}=g(t)+\frac{\Delta t}{2} g^{\prime}(t)+\frac{\Delta t^{2}}{4} g^{\prime \prime}(t)+0\left(\Delta t^{3}\right) .
$$

It follows from (3.11) that the "penalty" term in (3.8) introduces an error of $\left(\Delta t^{3}\right)$. Since the coefficient of $\left(\Delta t^{3}\right),\left[f_{u u}\left(u_{t}\right)^{2}\right]_{0}$, cannot generally be expressed as a function of $g(t)$ and 
its derivatives, it is very difficult to remedy the situation. Thus the "linear procedure" fails at the third RK stage.

We now propose a methodology to deal with the RK integration of non-linear hyperbolic conservation laws. We first present this procedure in the case of the classic 4th order R-K scheme. Our starting point is the observation that the "linear-procedure" yields the required accuracy for $v_{0}^{(n)}$ and $v_{0}^{(1)}$. The idea is to use at each stage a linear combination of the "linear" SAT, or penalty, terms used (3.5) and (3.6). The 4 th order classic RK stages will thus be:

$$
\begin{gathered}
V^{(1)}=V^{(n)}+\frac{\lambda}{2} D f\left(V^{n}\right)-\frac{\lambda}{2} \alpha \vec{\sigma}\left[v_{0}^{(n)}-g(t)\right] \\
V^{(2)}=V^{(n)}+\frac{\lambda}{2} D f\left(V^{(1)}\right)-\frac{\lambda}{2} \beta \vec{\sigma}\left[v_{0}^{(1)}-g(t)-\frac{\Delta t}{2} g^{\prime}(t)\right]-\frac{\lambda}{2} \gamma \vec{\sigma}\left[v_{0}^{(n)}-g(t)\right] \\
V^{(3)}=V^{(n)}+\lambda D f\left(V^{(2)}\right)-\lambda \delta \vec{\sigma}\left[v_{0}^{(n)}-g(t)\right]-\lambda \varepsilon \vec{\sigma}\left[v_{0}^{(1)}-g(t)-\frac{\Delta t}{2} g^{\prime}(t)\right] \\
V^{(n+1)}=V^{(n)}+\frac{\lambda}{6} D\left[f\left(V^{n}\right)+2 f\left(V^{(1)}\right)+2 f\left(V^{(2)}\right)+f\left(V^{(3)}\right)\right] \\
-\frac{\lambda}{6} \mu \vec{\sigma}\left[v_{0}^{(n)}-g(t)\right]-\frac{\lambda}{3} \nu \vec{\sigma}\left[v_{0}^{(1)}-g(t)-\frac{\Delta t}{2} g^{\prime}(t)\right]
\end{gathered}
$$

where the free parameters $\alpha, \beta, \gamma, \delta, \varepsilon, \mu$, and $\nu$ will be chosen so as to maximize the allowable time step. It is clear from the previous discussion that the system (3.12) - (3.15) maintains the 4 th order accuracy. There remains the question of whether the CFL stability condition deteriorates, in comparison to the conventional application of $\mathrm{R}-\mathrm{K}$, equation (2.4) - (2.7). It is also clear that the optimal choice of the free parameters $\alpha, \ldots, \nu$ varies with the spatial discretizations (i.e. the differentiation matrix $D$ ) and boundary closures. One cliecks that the absolute values of the eigenvalues of the amplification matrix resulting from (3.12) (3.15) should not exceed unity. We carried out this procedure (using Matematica Software) in the case of an explicit 4th order algorithm with 3rd order boundary closures. In this case $H=1$, and the matrices $P$ and $Q$ can be found in section (9.1) of reference [3]. With the following values of the free parameters, $\alpha=\beta=-\varepsilon=1, \delta=2, \mu=0, \nu=3, \gamma=-0.37$, the CFL condition becomes $\lambda \leq 2.1$. This is the same restriction on the time step, $\Delta t$, as one has in the linear problem using the "conventional", i.e. less accurate, boundary values witl or without the SAT-term.

\section{Conclusions}

In summary, we have in (3.12)-(3.15) a 4th order R.K scheme, applied to a non-linear p.d.e., which maintains the overall 4 th order accuracy without any decrease in the allowable time step. The extension to a system of hyperbolic p.d.e.'s is quite straight forward using the SAT-system approach delineated in ([3]). 


\section{References}

[1] O. Kreiss and J. Oliger, Comparison of Accurate Methods for the Integration of Hyperbolic Problems, Tellus V24, (1972), ’ेp.199-215.

[2] M.H. Carpenter, D. Gottlieb, S. Abarbanel and W.S. Don , The Theoretical Accuracy of Runge-Kutta Time Discretizations for the Initial Boundary Value Problem: A Study of the Boundary Error. To appear in SIAM Journal on Scientific Computing, ICASE report 93-83.

[3] M.H. Carpenter, D. Gottlieb, and S. Abarbanel, Time-Stable Boundary Conditions for Finite-Difference Schemes Solving Hyperbolic Systems: Methodology and Application to High-Order Compact Schemes, NASA Contractor Report 191436, ICASE Report No. 93-9, March 1993. To appear in JCP.

[4] M.H. Carpenter, D. Gottlieb, and S. Abarbanel, Stable and Accurate Boundary Treatments for Compact, High Order Finite Difference Schemes, Applied Numer. Math., 12 (1993) pp. 55-87. 



\begin{tabular}{|c|c|c|c|}
\hline \multicolumn{3}{|c|}{ REPORT DOCUMENTATION PAGE } & $\begin{array}{l}\text { Form Approved } \\
\text { OMB No. } 0704-0188\end{array}$ \\
\hline \multicolumn{4}{|c|}{ 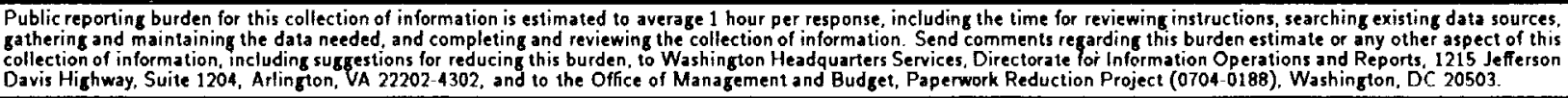 } \\
\hline 1. AGENCY USE ONLY(Leave blank) & $\begin{array}{l}\text { 2. REPORT DATE } \\
\text { September } 1994\end{array}$ & \multicolumn{2}{|c|}{$\begin{array}{l}\text { 3. REPORT TYPE AND DATES COVERED } \\
\text { Contractor Report }\end{array}$} \\
\hline \multicolumn{3}{|c|}{$\begin{array}{l}\text { 4. TITLE AND SUBTITLE } \\
\text { ON THE REMOVAL OF BOUNDARY ERRORS CAUSED BY } \\
\text { RUNGE-KUTTA INTEGRATION OF NON-LINEAR PARTIAL } \\
\text { DIFFERENTIAL EQUATIONS }\end{array}$} & \multirow[t]{2}{*}{$\begin{array}{l}\text { 5. FUNDING NUMBERS } \\
\text { C NAS1-19480 } \\
\text { WU 505-90-52-01 }\end{array}$} \\
\hline \multicolumn{3}{|c|}{$\begin{array}{l}\text { 6. AUTHOR(S) } \\
\text { Saul Abarbanel } \\
\text { David Gottlieb } \\
\text { Mark H. Carpenter }\end{array}$} & \\
\hline \multicolumn{3}{|c|}{$\begin{array}{l}\text { 7. PERFORMING ORGANIZATION NAME(S) AND ADDRESS(ES) } \\
\text { Institute for Computer Applications in Science } \\
\text { and Engineering } \\
\text { Mail Stop 132C, NASA Langley Research Center } \\
\text { Hampton, VA 23681-0001 }\end{array}$} & $\begin{array}{l}\text { 8. PERFORMING ORGANIZATION } \\
\text { REPORT NUMBER } \\
\text { ICASE Report No. } 94-79\end{array}$ \\
\hline \multicolumn{3}{|c|}{$\begin{array}{l}\text { 9. SPONSORING/MONITORING AGENCY NAME(S) AND ADORESS(ES) } \\
\text { National Aeronautics and Space Administration } \\
\text { Langley Research Center } \\
\text { Hampton, VA 23681-0001 }\end{array}$} & $\begin{array}{l}\text { 10. SPONSORING/MONITORING } \\
\text { AGENCY REPORT NUMBER } \\
\text { NASA CR-194989 } \\
\text { ICASE Report No. } 94-79\end{array}$ \\
\hline \multicolumn{4}{|c|}{$\begin{array}{l}\text { 11. SUPPLEMENTARY NOTES } \\
\text { Langley Technical Monitor: Michael F. Card } \\
\text { Final Report } \\
\text { To be submitted to Journal of Computational Physics }\end{array}$} \\
\hline \multicolumn{2}{|c|}{$\begin{array}{l}\text { 12a. DISTRIBUTION/AVAILABILITY STATEMENT } \\
\text { Unclassified-Unlimited } \\
\text { Subject Category } 64\end{array}$} & & 12b. DISTRIBUTION CODE \\
\hline \multicolumn{4}{|c|}{$\begin{array}{l}\text { 13. ABSTRACT (Maximum } 200 \text { words) } \\
\text { It has been previously shown that the temporal integration of hyperbolic partial differential equations may, because } \\
\text { of boundary conditions, lead to deterioration of accuracy of the solution. A procedure for removal of this error } \\
\text { in the linear case has been established previously. In the present paper we consider hyperbolic p.d.e's (linear and } \\
\text { non-linear) whose boundary treatment is done via the SAT-procedure. A methodology is present for recovery of the } \\
\text { full order of accuracy, and has been applied to the case of a 4th order explicit finite difference scheme. }\end{array}$} \\
\hline \multirow{2}{*}{\multicolumn{3}{|c|}{$\begin{array}{l}\text { 14. SUBJECT TERMS } \\
\text { 4th order Runge-Kutta, Time-dependent boundary conditions, hyperbolic p.d.e.'s }\end{array}$}} & $\begin{array}{l}\text { 15. NUMBER OF PAGES } \\
9\end{array}$ \\
\hline & & & $\begin{array}{c}\text { 16. PRICE CODE } \\
\mathrm{A} 03 \\
\end{array}$ \\
\hline $\begin{array}{l}\text { 17. SECURITY CLASSIFICATION } \\
\text { OF REPORT } \\
\text { Unclassified }\end{array}$ & $\begin{array}{l}\text { 18. SECURITY CLASSIFICATION } \\
\text { OF THIS PAGE } \\
\text { Unclassified }\end{array}$ & $\begin{array}{l}\text { 19. SECURITY CLASSIFICATION } \\
\text { OF ABSTRACT }\end{array}$ & $\begin{array}{l}\text { 20. LIMITATION } \\
\text { OF ABSTRACT }\end{array}$ \\
\hline NSN 7560-01-260-5500 & S. GOVERNMENT PRINTING OFFCE: Wy & & $\begin{array}{l}\text { Standard Form } 298(\text { Rev. } 2-89) \\
\text { Prescribed by ANSI Std. Z39-18 }\end{array}$ \\
\hline
\end{tabular}


National Aeronautics and

Space Administration

Langley Research Center

Mail Code 180

Hampton, VA 23681-00001

Orifelal Bualneas

Pendity for Privatis Uea, 5300
BULK RATE

POSTAGE \& FEES PAID NASA

Permit No. G-27 
